\title{
Consideraciones científicas y éticas en las perspectivas diagnósticas y terapéuticas en medicina fetal
}

\author{
Enrique Valdés $\mathbf{R}^{1}$, Emiliano Soto-Chacón ${ }^{2}$, Silvia Castillo $\mathbf{T}^{3}$. \\ Scientific and ethical perspectives \\ of perinatal and fetal medicine
}

This review emphasizes the importance of recent developments and knowledge on cell biology and human genetics than have integrated, through a basic-clinical concept, to an emerging branch of medicine, called Perinatal and Fetal Medicine. We discuss the possible role of fetal cells and DNA in the diagnosis and treatment of diseases in the intrauterine environment. The associated bioethical issues associated to these medical actions are discussed, considering the imminent use of these agents in the human species (Rev Méd Chile 2008; 136: 1197-202).

(Key words: Bioethics; DNA; Fetal stem cells; Perinatal care)

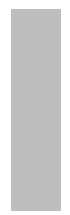

\begin{abstract}
Recibido el 21 de agosto, 2007. Aceptado el 18 de marzo, 2008.
${ }^{1}$ Unidad de Medicina Materno Fetal, Departamento de Obstetricia y Ginecología, Hospital Clínico de la Universidad de Chile. ${ }^{2}$ Programa de Doctorado en Ciencias Médicas y Formación de Especialista en Obstetricia y Ginecología, Facultad de Medicina, Universidad de Chile. ${ }^{3}$ Unidad de Genética. Departamento de Medicina. Hospital Clínico de la Universidad de Chile. Santiago de Chile.
\end{abstract}

$\mathrm{H}$ istóricamente, el acercamiento al conocimiento del feto y su ambiente intrauterino ha sido tratado bajo el prisma del misticismo. Es así que en un intento de explicar la relación entre el feto y el niño, los pensadores grecorromanos concibieron la idea del Humunculus. Las observaciones del feto humano estuvieron limitadas a abortos ocasionales del Humunculus, una persona en miniatura viviendo y creciendo dentro de la madre antes del parto por lo que el desarrollo de la anatomía y fisiología fetal derivó casi exclusivamente de las observaciones hechas de éste.

Posteriormente, Darwin termina por desmitificar el rol de la reproducción al sostener que: «..el

Correspondencia a: Dr. Enrique Valdés Rubio. Departamento de Obstetricia y Ginecología, Unidad de Medicina Fetal, Hospital Clínico Universidad de Chile. Santos Dumont 999, sector A, $1^{\mathrm{er}}$ piso. Independencia, Santiago. E mail: evaldes@vtrnet hombre es desarrollado a partir de un óvulo que mide $\pm 0,125$ pulgadas de diámetro, el cual no difiere de un óvulo animal...».

Estas aseveraciones, el desarrollo científico y la concepción cartesiana fueron las que permitieron que en los inicios del siglo XX el feto fuera objeto de una descripción biológica, marcando el interés científico para conocer al feto como un paciente, a quien frente a su patología se le podría ofrecer diagnóstico y tratamiento. Es con relación a estos dos últimos tópicos donde se enfatizará la importancia del desarrollo del conocimiento de la biología celular y de la genética humana en el último tiempo, disciplinas que se han integrado en un concepto «ásico-clínico»ampliando las potencialidades de una nueva especialidad en la medicina como lo es la «Medicina Fetal y Perinatal».

A continuación se desamollará en forma sucinta tópicos relacionados al eventual rol de las células, el $\mathrm{ADN}$ fetal y el uso de células madres en el diagnóstico 
y tratamiento de patologías dentro del ambiente intrauterino, aportando a la discusión elementos éticos relacionados con este fin, ante la inminente utilización de éstos en la especie humana.

\section{PerSPeCtivas diagnósticas PRENATALES}

Células fetales y ADN libre fetal. Desde hace ya más de un siglo (1893) Schmorl publicó la presencia de células trofoblásticas en el tejido pulmonar en 14 de 17 gestantes que fallecieron producto de una crisis eclámptica ${ }^{2}$. Posteriormente, Atwood \& Park (1960) confirmaron los hallazgos de Schmorl, observándolo además en otras condiciones patológicas que afectaban el embarazo ${ }^{3}$. Todo lo anterior, ha llevado a convertir al aislamiento de células fetales en sangre materna y su empleo como método diagnóstico prenatal en un tema candente en la investigación actual. Según numerosos estudios este microquimerismo (coexistencia de células de origen embrionario distinto) tendría relación con el desarrollo de enfermedades autoinmunes en la mujer embarazada, lo anterior apoyado por el aislamiento de células o ADN fetal en las lesiones dérmicas maternas de patologías de origen mesenquimático, tales como la escleroderma y la erupción polimórfica del embarazo ${ }^{4}$.

Por otro lado, anteriormente Ganshirt-Ahlert et al en $1994^{5}$, ya habían publicado la presencia de un mayor número de eritroblastos fetales en el torrente sanguíneo de mujeres con preeclampsia. Recientes estudios reafirmaron lo anteriormente expuesto, aseverando incluso que una placentación alterada estaría asociada a un aumento del tráfico de células fetales hacia el territorio materno y que ésta precedería en varias semanas a la aparición de preeclampsia (PE) o restricción de crecimiento intrauterino (RCIU) ${ }^{6,7}$.

Posteriormente gracias al conocimiento acumulado en el campo de la biología celular, biología molecular y genética humana, ha sido posible aislar en territorio materno células fetales o ADN libre fetal, estructuras que no sólo nos permiten establecer el diagnóstico prenatal de patologías con etiología genética (monogénicas) y cromosómica (numérica o estructural), sino también nos servirían como herramientas diagnósticas en la pesquisa precoz de patologías con eventual impacto materno $(\mathrm{PE})^{8}$.
Numerosos métodos han sido empleados con el fin de detectar y cuantificar células fetales en sangre materna con el fin de ser utilizadas en el diagnóstico de aneuploidías, pero dado el escaso y variable número de células, una a mil células fetales por cada diez millones de células maternas, estos métodos no han podido ser empleados rutinariamente $^{9,10}$. Para tal efecto, en el último tiempo se han perfeccionado métodos como la citometría de flujo (FACS) y la clasificación magnética de células (MACS) en la cuantificación y separación de células fetales en sangre materna, específicamente de eritroblastos fetales. Se ha seleccionado este tipo de células eritroides en el diagnóstico prenatal debido a que estas células son abundantes en el territorio fetal, presentan una vida media corta (30 días) y son excepcionalmente aisladas en sangre de personas adultas. En contraposición las células linfáticas fetales, se encuentran en un número menor y cuentan con vidas medias largas (5 a 27 años), por lo que pueden perdurar en sangre materna el tiempo suficiente para inducir a errores diagnósticos en embarazos posteriores ${ }^{7}$.

Para la utilización de las células fetales en el diagnóstico exitoso de aneuploidías (trisomías 13, 18, 21, X e Y) y trastornos de un solo gen en el muestreo materno, fue necesario salvar importantes obstáculos que permitieran el análisis de pocas células sin división. Esto último se resolvió gracias al desarrollo de técnicas biomoleculares, entre ellas la técnica de hibridación in situ con fluorescencia (FISH) ${ }^{11}$ que permitió el estudio cromosómico de células en reposo durante la interfase y la reacción en cadena polimerasa (PCR) ${ }^{12}$ que facilitó el análisis de rasgos genéticos en células aisladas.

Por otra parte, con la aplicación de estos métodos diagnósticos no sólo es posible realizar diagnósticos prenatales por medio de biopsia de vellosidad corial, amnio y cordocentesis genética, sino que también se ha desarrollado el diagnóstico pre implantacional (DPI), método ofrecido a aquellas pacientes sometidas a técnicas de fertilización in vitro (IVF) que por sus antecedentes presenten un mayor riesgo de transmitir a su descendencia un trastorno específico genético aislado o un desequilibrio cromosómico.

Células madre. El vertiginoso avance de las ciencias y del conocimiento del ser humano nos muestra en 
la actualidad líneas de investigación conducentes al conocimiento de cómo un organismo complejo se puede derivar a partir de una célula y cómo es posible hoy lograr que células sanas sustituyan a células dañadas en órganos de un adulto a través de terapias regeneradoras o reparativas.

La base científica de lo anterior lo constituyen células multipotenciales, obtenidas de embriones o células adultas que se denominan células madre, células troncales o estaminales.

Una definición universalmente aceptada de células madre (Células Estaminales, Stem Cells, Embryo Stem Cells) es de aquella célula que cuenta con dos características: a) Capacidad de renovación ilimitada, es decir que presente la posibilidad de reproducirse muchas veces sin diferenciarse; y b) Capacidad de dar origen a células madre de transición, con multiplicación limitada, de las cuales derivan una variedad de cepas celulares altamente diferenciadas (nerviosas, musculares, hemáticas) ${ }^{13,14}$.

Desde hace algunos años las células madre (CM) han sido objeto de intensa investigación, aislándose principalmente a partir de tejidos embrionarios, cultivos in vitro en animales de experimentación y en tejidos adultos, todo lo cual ha implicado una gran discusión tanto en los campos de la clínica como en el de la ética.

El método para obtenerlas está aún en estudio, pero la inoculación de células troncales humanas en animales de experimentación (ratones) o su cultivo in vitro en terreno acondicionado, han demostrado la capacidad de dar origen a células diferenciadas que se obtendrían a partir de las tres capas embrionarias: endodermo, mesodermo y ectodermo, representando el punto de partida para la preparación de líneas celulares diferenciadas: musculares, nerviosas, epiteliales, hemáticas y germinales, entre otras ${ }^{15}$.

Estos resultados han motivado al mundo científico y tecnológico, como asimismo a los medios de comunicación social a generar grandes esperanzas en la búsqueda de nuevas y más seguras soluciones para la terapia de enfermedades graves, pero por otra parte han llevado al mundo a reflexionar sobre las implicancias legales y éticas que conllevan los nuevos descubrimientos.

Células madres del adulto. Como se ha expuesto anteriormente, las CM pueden ser aisladas a partir de embriones producto de abortos espontáneos 0 inducidos, o de embriones sobrantes de programas de fecundación in vitro o de embriones producidos exclusivamente con este fin. Aunque cada origen produce gran debate en todos los niveles de la sociedad y en los diferentes países que cuentan con esta potencial herramienta terapéutica, es importante destacar que Inglaterra es el único país del mundo en que la clonación terapéutica, entendida como aquella que permite la obtención de CM a partir de embriones producidos con fines terapéuticos, es permitida. Por lo que implica este debate, sólo se referirá al rol de $\mathrm{CM}$ de origen adulto (CMA) en el tratamiento de patologías durante la vida fetal, ya que comparten mayor consenso científico y moral en su utilización para este fin ${ }^{16,17}$.

Clásicamente, las investigaciones en células madre del adulto (CMA) (Adult Stem Cells o Células Estaminales del adulto) han concluido que pueden ser aisladas en diversos tejidos adultos, con la salvedad de dar origen sólo a células propias de un determinado tejido, es decir sin la posibilidad de su reprogramación. Sin embargo, actualmente se descubre que en determinados tejidos humanos adultos es posible aislar CMA pluripotenciales, esto es, capaces de dar origen a diversos tipos de células a partir de CMA obtenidas en la médula ósea (HSCs), en el cerebro (NSCs) y en la sangre del cordón umbilical (PCB, placental cord blood).

Con relación a la terapéutica, cabe destacar que diferentes autores concuerdan con el prometedor éxito del uso de las CMA en el tratamiento de patologías tan disímiles como las de origen miogénico, hematopoiético y neuronal.

Por otro lado, a partir de diagnósticos prenatales más precoces podremos planificar estrategias terapéuticas intrauterinas o postnatales ${ }^{18}$. Teóricamente, existirían ventajas del tratamiento prenatal versus el neonatal, ventajas que el período fetal ofrece y que les son únicas y que a continuación se enumeran: 1) En este período existe gran proliferación con expansión exponencial de los compartimientos celulares. 2) Es la única etapa en la vida cuando ocurren migraciones de CMA en gran escala para sembrar compartimientos anatómicos para el desarrollo de tejidos diferenciados. 3) El feto es pequeño, aproximadamente $75 \mathrm{~g}$ antes de las 13 semanas, lo que lo transforma en 
un receptor óptimo en términos de poder permitir ser receptor de una dosis mucho mayor de CMA por kilogramo que lo que puede lograrse después del nacimiento, y 4) La tolerancia inmune fetal, este último punto quizá es el que representa una mayor ventaja, ya que el sistema inmune gestacional incipiente está en proceso de autoinstrucción, período que ocurre esencialmente en el timo fetal y que consta de dos etapas: la primera de ellas destinada a la selección positiva de prelinfocitos con el objetivo de reconocer aquellos antígenos spropios»del complejo mayor de histocompatibilidad (MHC) y la segunda donde prevalece una selección negativa de prelinfocitos, fenómeno denominado deleción, que da la posibilidad de reconocer como propios» aquellos antígenos extraños que son presentados junto al MHC ${ }^{19-21}$.

Con relación a este tipo de terapia, quizá donde se tenga una mayor experiencia es con el uso de células madre hematopoyéticas (HSC) en el tratamiento de fetos portadores de una amplia variedad de enfermedades tales como; hemoglobinopatías, inmunodeficiencias y errores congénitos del metabolismo. Debido al éxito reducido demostrado en estas experiencias clínicas, es que se ha concluido que aún existen barreras» que no han podido ser superadas por la tecnología actual. Dentro de estas barreras»se deben considerar: 1) El grado de quimerismo logrado en el feto trasplantado es limitado por falta de «espacio» disponible en el tejido receptor ${ }^{22}$. 2) El éxito del trasplante de HSC depende de la población celular competitiva del huésped 22,23 y 3) En la actualidad, a pesar de lo avanzado que está el conocimiento del rol que cumple el sistema inmune en la dinámica de tolerancia fetal, aún se desconocen una serie de factores de rechazo que lo transforman en una barrera a salvar ${ }^{24-27}$.

Transferencia intrauterina de genes. Aunque los vectores retrovirales y adenovirales se han utilizado en la terapia génica prenatal, la utilización de éstos en clínica, parece lejana. Lo anterior está avalado por una serie de tópicos científicos y éticos no resueltos, entre ellos están los riesgos indefinidos de integración de línea germinal, alteración de desarrollo normal, mutagénesis de inserción, generación de virus recombinantes y la inducción de tolerancia prenatal a un virus patógeno ${ }^{28}$. Esto sin mencionar, que aún no se han podido elaborar técnicas de transferencia de genes que avalen la seguridad de contar con expresión regulada a largo plazo de la proteína deseada y específica de cada tejido ${ }^{29}$.

En resumen, la terapia fetal basada en la utilización de células madre o genes es una posibilidad cada vez más promisoria en el tratamiento de enfermedades que afectan al feto, al neonato 0 al adulto. Pero es de suma importancia por una parte, seguir investigando una serie de factores fetales que puedan actuar como barrera en el éxito de esta terapia y por otra, aclarar una serie de dudas éticas que involucra la utilización de estas técnicas.

Discusión ética. La investigación científica en beneficio del hombre representa una esperanza para la humanidad, encomendada al genio y al trabajo de los científicos, cuando tiende a buscar remedio a las enfermedades, aliviar el sufrimiento, resolver los problemas debidos a la insuficiencia de alimentos y a la mejor utilización de los recursos de la tierra.

Por otro lado, los principios éticos fundamentales aplicables a la investigación con células estaminales humanas involucran: el respeto a la dignidad humana, el principio de autonomía (que engloba consentimiento informado y respeto por la confidencialidad de datos personales), el principio de justicia y beneficencia, el principio de libertad de investigación y el principio de proponcionalidad.

La clonación reproductiva está prohibida en seres humanos por la Declaración Universal sobre el Genoma Humano y los Derechos Humanos, resolución ratificada por la Conferencia General de la UNESCO (1997) y refrendada posteriormente por la Asamblea General de las Naciones Unidas. Sin embargo, la clonación terapéutica sigue siendo objeto de intenso debate religioso, fundamentalista y científico ${ }^{30}$.

Desde una perspectiva ética, los problemas que genera la utilización de embriones apunta para algunos a la validez de la utilización de embriones vivos para la preparación de células estaminales a partir de la clonación terapéutica, las otorgadas por otros investigadores o las disponibles en el mercado ${ }^{31,32}$.

Por lo tanto, la discusión abarca esferas más amplias que la simple utilización de células troncales. Para algunos la manipulación de embriones se enmarca en un proyecto de eugenismo. Para otros, 
trabajar con embriones implica a lo menos, una instrumentalización de la mujer. Por lo que todo tipo de clonación terapéutica que implique la producción de embriones humanos con el fin de obtener CM por medio de la manipulación 0 destrucción de los embriones producidos, es ilícita. Lo anterior basado en que esta técnica sería una manipulación radical de la relacionalidad y complementariedad constitutivas que están en la base de la procreación humana, tanto en su aspecto biológico como en el propiamente personal ${ }^{32,33}$.

Mientras la obtención de células troncales provenga de tejidos adultos, se declara lícito, ética y moralmente un procedimiento aceptable, a diferencia de lo que ocurre cuando su producción proviene de embriones, representando en este caso la producción de células troncales o estaminales un foco de intenso debate ${ }^{30-34}$.

Con relación a los aspectos legales la situación es a todas luces dispar. Mientras en algunos países existen leyes específicas que permiten la investigación con células estaminales embrionarias, en otros se prohíbe el uso de embriones humanos para la obtención de células estaminales, pero se permite la importación de dichas células en ciertos casos que no se especifican claramente, o se prohíbe en toda circunstancia la investigación con células estaminales embrionarias o simplemente no se tiene legislación específica ${ }^{35}$.

\section{ConClusiones}

La desmitificación del feto y su ambiente intrauterino como consecuencia de la evolución del conocimiento del hombre, transformándolo en un ser que ha abandonado el dogma en pro del razonamiento científico, ha hecho posible el desarrollo de una serie de técnicas en el campo de la medicina que le han aportado la posibilidad de introducir herramientas diagnósticas y terapéuticas capaces de ofrecer a este paciente aún no nacido, oportunidades sanativas o paliativas a enfermeda-

\section{REFERENCIA}

1. HaRrison M. The fetus as a patient: Historical Perspective. Cap 1: pags. 3-7. The unborn pacient. Prenatal diagnosis and treatment. Harrison M, Gol- des que hasta hace muy poco eran inimaginables de poder abordar.

Desde fines del siglo pasado se ha logrado estudiar material genético y células fetales en el torrente sanguíneo materno que han otorgado un prometedor avance en el diagnóstico precoz de patologías que afectan al binomio madre-hijo (PE, RCIU, cromosomopatías o genopatías), algunas de ellas potencialmente susceptibles de ser prevenidas. Del mismo modo, gracias al desarrollo de la ingeniería genética y de la medicina es posible tratar enfermedades degenerativas por medio de $\mathrm{CM}$ de origen embrionario o adulto. En este sentido, es evidente la seriedad y la gravedad del problema ético abierto por la voluntad de extender al campo de la investigación humana, la producción o el uso de embriones humanos, incluso desde una perspectiva humanitaria.

Por otra parte, frenar o no el proyecto de la clonación humana es un compromiso moral que debe traducirse también en términos culturales, sociales y legislativos. En efecto, el progreso de la investigación científica debe promulgar su desarrollo a partir del respeto de la vida humana basándose en el seguimiento de las normas bioéticas consensuadas por las diferentes sociedades.

La posibilidad de utilizar células estaminales adultas para lograr los mismos fines que se pretenden alcanzar con las células estaminales embrionarias, indica esta posibilidad como la vía más razonable y humana que se ha de seguir para un correcto y válido progreso en este nuevo campo que se abre a la investigación y a prometedoras aplicaciones terapéuticas. Estas representan, sin duda alguna, una gran esperanza para personas enfermas, que hasta ahora padecían de patologías sin soluciones terapéuticas.

\section{Agradecimientos}

A los doctores Hugo Salinas P. y Sergio Valenzuela P. quienes con su valiosa cooperación y sugerencias hicieron posible la confección de este artículo.

bus M, Filly R. Editorial W.B. Saunders Company. 1991. USA. http://stemcells.nih.gov

2. SсномовL G. Pathologisch-anatomische Untersuchungen über Puerperal-Eklampsie, Verlag FCW Vogel, Leipzig (1893). 
3. Attwood HD, Park WW. Embolism to the lungs by trophoblast. J Obstet Gynaecolo Br Commonw 1961; 68: 611-7.

4. NeLSON JL. Pregnancy inmunology and autoinmune diseaser. J Reprod Med 1998; 43: 335-40.

5. PERT B, BiAnchi DW. Fetal DNA in maternal plasma: emerging clinical applications. Obstet Gynecol 2001; 98: 483-90.

6. Gänshirt-Ahlert D, Basak N, Aidynu K, Holzgreve W. Fetal DNA in uterine vein blood. Obstet Gynecol 199; 80: 601-3.

7. Al-Mufti R, Hambley $H$, Farzaneh $F$, Nicolaides KH. Investigation of maternal blood enriched for fetal cells: role in screening and diagnosis of fetal trisomies. Am J Med Genet 1999: 85: 66-75.

8. Hozgreve W, Garritsen HS, Ganshirt-Ahlert D. Feta cells in the maternal circulation. J Reprod Med 1992; 37: 410-8.

9. Al-Mufti R, Hambley H. Albaiges G, Lees C. Nicolaides $\mathrm{KH}$. Increased fetal erythroblasts in women who subsequently develop pre-eclampsia. Hum Reprod 2000; 15: 1624-8.

10. Holzgreve W, Li JJ, Steinborn A, Kulz T, Sohn C, Hodel M, HaHN S. Elevation in erythroblast count in maternal blood before the onset of preeclampsia. Am J Obstet Gynecol 2001; 184: 165-8.

11. Kunger K, Landes G, SHook D. Rapid Detection of chromosome aneuploidies in uncultured amniocytes by using fluorescence in situ hybridization (FISH). Am J Hum Genet 1992; 51: 55-65.

12. MuLuS K, Faloona F, Scharf S. Specific enzymatic amplification of DNA in vitro: the polymerase Caín reaction. Cold Spring Harb Symp Quant Biol 1986; 51: 263-73.

13. VAN DER KoOy D, WeISS S. Why stem cells? Science 2000; 287: 1439-41.

14. Thomson Ja, Itskovitz-EldorJ, Shapiro SS, Waknitz MA, SwiERgiel JJ, MarShall VS ET aL. Embryonic stem cell lines derived from human blastocysts. Science 1998: 282: $1145-7$.

15. Nagy A, Rossant Nagy, Abramow-Newerly W, Roder JC. Derivation of completely cell culture-derived mice from early-passage embryonic stem cells. Proc Nat Acad Sci 1993; 90: 82424-8.

16. Mons. Favalora JC. Declaración de la academia pontificia para la vida sobre la producción y uso científico y terapéutico de las células estaminales embrionarias humanas. Ciudad del Vaticano. Librería Editora Vaticana, 2000.

17. European Group on Ethics in Science and New Technologies to the European Comission. Ethical aspects of human stem cell research and use. Bruselas, 2000.
18. Hahn S, Sant R, Holzgreve W. Fetal cells in maternal blood: current and future perspectives. Mol Hum Reprod 1998: 4: 515-21.

19. Holzgreve W, Hahn S. Prenatal diagnosis using fetal cells and free fetal DNA in maternal blood. Clin Perinatol 2001; 9: 353-65.

20. Hulett HR, Bonner WA, Barrett J, Herzenberg LA. Cell sorting: automated separation of mammalian cells as a function of intracellular fluorescence. Science 1969; 166: 474-49.

21. Radbruch A, Mechtol B, Thiel A. High-gradient magnetic cell sorting. Methods Cell Biol 1994; 42: 387-403.

22. Holzgreve W. Will ultrasound-scrrening and ultrasoun-guided procedures be replaced by non-invaisve techniques for the diagnosis of fetal chromosome anomalies? Ultrasound Obstet Gynecol 1997; 9: 217-9.

23. Takabayashi $H$, Kuwabara S, Ukita T. Development of noninvasive fetal DNA diagnosis from maternal blood. Prenat Diagn 1995; 15: 74-7.

24. Sekizawa A, Watanabe A, Kimura T. Prenatal diagnosis of the fetal RhD Blood Type using a single fetal nuclated erythrocyte from maternal blood. Obstet Gynecol 1996; 87: 501-5.

25. Samura O, Sohda S, Jonson KL. Diagnosis of trisomy 21 in fetal nucleated erythrocytes from maternal blood by use of short tandem repeat sequences. Clin Chem 2001; 47: 1622-6.

26. Schutze K, Becker I, Becker KF. Cut out or poke inthe key to the world of slingle genes: laser micromanipulation as a valuable tool on the look-out for the origien of disease. Genet Anal 1997; 14: 1-8.

27. VAierio D, AieiLo R, Altieri V. Culture of fetal erythroid progenitor cells from matemal blood for noninvasive prenatal genetic diagnosis. Prenat Diag 199; 16: 1073-82.

28. Prenatal gene tranfer: scientific, medical, and ethical issues: a report of the Recombinant DNA Advisory Committee. Hum Gene Ther 2000; 11: 1211-29.

29. FlaKe A. Genetic therapies for the fetus. Clin Obstet Gynecol 2002; 45: 684-96.

30. Mitchel P. Los gobiemos ponen freno a la investigación sobre células troncales. En: www.wsws.org Word Socialist Site. Consultado el 20/12/2007.

31. Commission of the European Communities. Report on Human Embryonic Stem Cell Research. Bruselas, 2003.

32. Mons. Favalora JC. Reflexiones sobre la clonación. Ciudad del Vaticano. Librería Editora Vaticana, 1997.

33. Sieguel AW. Temporal restrictions and the impasse on human embryonic stem-cell research. Lancet 2004; 364: 215-8.

34. It is time for scientists to make the case for stem-cell research. Lancet 2004; 364: 113-4.

35. TAUER CA. International policy failures: cloning and stem-cell research. Lancet 2004; 364: 209-14. 